\title{
Testing the waters: TikTok's potential for television news
}

\author{
Karina Chobanyan ${ }^{1}$ \\ Elina Nikolskaya \\ Lomonosov Moscow State University, Russia
}

To cite this article: Chobanyan, K., \& Nikolskaya, E. (2021). Testing the waters: TikTok's potential for television news. World of Media. Journal of Russian Media and Journalism Studies 3. DOI: 10.30547/worldofmedia.3.2021.3

\begin{abstract}
TikTok has taken the world of mobile apps by storm. In a short period of time, it managed to become the destination of choice for most of the young users and it is currently witnessing the aging of its audience. Mass media has started to test the TikTok waters early in 2019. However, there are still very few TV news channels daring to take the risks and try to lure the TikTok audience to television news. In this article we are evaluating the field of TikTok news players and the platform's potential to become another popular source of serious information. We are closely analyzing the top two accounts of traditional TV news on TikTok: NBC News and CBS News. As it turns out, there is room for traditional TV formats and adapted for TikTok news bits. Politics remains one of the most demanded by the audience topics. And even though young users emphasize the importance of brevity and entertainment aspect for any potential TV news videos on TikTok, our study results show that even serious and least entertaining videos can get millions of likes and views.
\end{abstract}

\section{Keywords}

TikTok, television news, digital platforms, mobile news consumption, traditional TV news.

\section{Introduction}

TikTok has rapidly turned into one of the most popular mobile apps. According to Sensor Tower Intelligence, it has over 2 billion downloads worldwide, and in

\footnotetext{
${ }^{1}$ Corresponding author:

Karina Chobanyan, Lomonosov Moscow State University, Faculty of Journalism, 9, Mokhovaya st, Moscow, Russia.

Email: kchobanyan@gmail.com
} 
Q1 2020 with 315 million global downloads it became the most popular mobile application. Almost 60 percent of its users represent Generation Z (Doyle, 2021), which is a typical story of young generation to be the first to embrace new technologies. However, there is evidence that TikTok's audience is slowly getting more mature: in the U.S. alone $16,4 \%$ of its users are $30-39$ years old, and almost $14 \%$ are between the ages of 40 and 49 (Nover, 2020). Globally, 18\% of Internet users ages 16-64 were on TikTok in 2020, which makes 13\% spike compared to 2018 (Mander et al, 2020). U.S., Indonesia, Russia, Japan and France are leading the list of countries with TikTok users (Williamson, 2020). In 2021 TikTok was reaching $24 \%$ of under-35s, while $7 \%$ were using it for news, according to most recent numbers (Newman, 2021).

Traditional media has already started to recognize the potential of this new platform in reaching new audience. U.S. channels NBC News and ESPN were among the first ones to register on TikTok early in 2019. American newspapers Washington Post and USA Today also joined them later in 2019.

So far TikTok is not even close to becoming the preferred source for news: only 3 percent of adult Americans report regularly getting news on TikTok (Shearer \& Mitchell, 2021), and news category does not fall into top ten hashtag views (Geyser, 2021). However, the platform obviously has potential for reaching the younger audience. According to Reuters Digital News report 2020, social media in general is increasing its share as the main gateway for news both for the 'All ages' group (up $2 \%$ to $26 \%$ overall) and for 'Generation Z' group in particular (up $2 \%$ to $38 \%$ overall) (Newman, 2020). And Covid-19 lockdown only spiked the popularity of the platform, as $11 \%$ of Americans ages 18-24 accessed Covid-19 news via TikTok (Newman, 2020). This further proves the trend of increased news consumption via Instagram, Snapchat and TikTok among young people. Overall, weekly online news video consumption, according to the same source, varies from $39 \%$ to $95 \%$ in different regions, with an average of $67 \%$ across 40 markets (Newman, 2020).

One of TikTok's main attractions for media is its storytelling tool (Rempel, 2020). The news outlets that dared to pioneer this platform have generated solid number of subscribers and likes: Washington Post $(907 \mathrm{~K} / 36 \mathrm{M})$, USA Today (898K/23M), ESPN (14M/900M), NBC News (714K/20M) ("all the numbers are as of April 1,2021).

This research aims to focus on exploring the niche of television news channels that have pioneered on TikTok and on analyzing the practices they are using to reach the new audience. We are interested in the topics that attract the audience, in the traditional and new formats the channels are using to 
produce the clips, in the changing (or not) role of the presenter, and in the video description techniques targeting the new users.

\section{Literature review}

Media communications studies outline the latest challenges journalists are facing with the arrival of new technologies and widening digital divide (Vartanova, Gladkova et al, 2021). Understanding the potential and the reach of popular online video platforms like TikTok is also an important factor for any media channel in the modern world.

Currently there are several research directions involving TikTok and other short videos platforms. Some focus on studying user behaviors (Wang, Gu \& Wang, 2019; 2020; Yu, 2019; Zhou, 2019), others on the addiction potential of short videos (Yang, 2018; Zhang, Wu \& Liu, 2019), on political and health communication via TikTok (Basch et al, 2020; Serrano et al, 2020; Zhu et al, 2019). Direct research of official media accounts on TikTok is also starting to appear, but the number of these studies so far is limited.

One of the studies is based on the user-centric theory. It highlights the vulgarization of TikTok's current content and the dangers of 'information cocoons', easily created by pushing content algorithm technology. The main user here is the audience, and TikTok's algorithms are built to meet the audience's needs through deep interaction. The author notes TikTok's potential in enriching the users' knowledge, providing quality content and adhering to the role of gatekeeper (Yu, 2019).

Wang, Gu \& Wang (Wang, Gu \& Wang, 2019) further explore user behaviors on short musical video platforms, focusing on TikTok and Kuai Shou. They combine the theory of uses and gratifications with social identity and media law to analyze internet communities forming around these platforms. The authors particularly note low thresholds for engagement which makes these communities (represented mostly by Generation Z) quite unstable.

TikTok and Bilibili are also in the center of studies of user behaviors on short video platforms, which result in pointing out five different persona types based on online activities and creative practices of short video platforms audience (Qiyang \& Jung, 2019; Zhou, 2019).

Short videos addiction potential in general is one of the popular research directions concerning TikTok. Some studies point out the whole chain of factors leading to short videos addiction: social interaction anxiety and social isolation, interpersonal and site attachments and even neuroticism as one of the positive moderators of site attachment (Zhang, Wu \& Liu, 2019). 
Meanwhile, TikTok's potential for becoming a valuable platform in spreading important health information has already been proved in several health communication studies (Basch et al, 2020; Zhu et al, 2019). Their main conclusion: professional sources of health information are struggling to take advantage of TikTok and missing their opportunities to tap into younger audience. Particularly, one of the studies focused on coronavirus hashtag. Even though the number of posts with this hashtag was relatively small (including the ones in the official account of World Health Organization), they received over one billion views. However, 'these videos provided little to no useful information' and represented 'a lost opportunity of monumental proportions' (Basch et al, 2020). Also, one of the recent studies focuses on the opportunities TikTok offers to radiology (Lovett et al, 2021).

Things are different with political communication on TikTok. One of the first studies in this direction found political content to be 'a relevant aspect of TikTok's ecosystem'. Also, with users below 40 years old, political communication on TikTok proved to be 'more interactive in comparison to other social platforms' (Serrano et al, 2020).

Pedagogical perspectives of TikTok are also being explored in 2021 studies. Some conclusions point educators towards using TikTok as a learning tool that 'enhances creativity and curiosity' (Escamilla-Fajardo, Alguacil \& L pez-Carril, 2021).

Television news channels and other media accounts on social networks have also been studied (Chobanyan, 2020; Nigmatullina, 2021), as well as some speech strategy algorithms and promotion techniques (Gavra, Bykova, 2021).

Finally, there are few recent studies of official media accounts on TikTok. Their focus is much closer to the research questions we are posing in this article. One of them mapped out the existing media accounts on TikTok (total of 234) and conducted content analysis of 19 verified news media and programs (newspapers, magazines, TV, radio and digital-native). The authors discover different adaptation techniques which make TikTok different from other social networks and conclude that TikTok is the place for indirect and incidental consumption of news (Vázquez-Herrero et al, 2020).

In the follow-up study they focus on 133 profiles of television channels and programs and try to discover their main strategies, although the researchers acknowledge that at this stage it's too early to talk about 'strategies' for most of the accounts. Yet, they classify the existing accounts according to their debut on TikTok, their genres and formats and their subscriber base. They also point out music and tags as the key for navigating the platform and for positioning 
TV content there. Overall though, the authors conclude that TV channels and programs have 'to think outside the box to reinvent television for the social network of the moment' (Vázquez-Herrero et al, 2021).

In this article we will closely examine the niche of television news and the options TikTok can offer to this segment. We will also analyze some specific practices the news channels and news programs are already trying out on TikTok.

The goal of this research is to find out what kind of transformations TV news channels are using to adapt their content to TikTok's format and audience consumption habits. We also want to find out whether the young audience is ready to consume news videos on TikTok.

The main research questions are:

RQ1: What are the main trends of the TV news channels' experience on TikTok so far and what kind of dynamics are they showing?

RQ2: Which content and formats are the most successful news channels presenting on TikTok?

$R Q 3$ : What kind of visuals, sounds and hashtags are they using? What kind of transformations are the texts in video descriptions going through? What makes it different from traditional TV news?

$R Q 4$ : Which news topics does the audience prefer?

RQ5: Can TV news exist on TikTok from younger audience's perspective?

\section{Hypothesis}

We expect to find that TV news videos on TikTok are moving towards entertainment both in terms of topics and presentation techniques. We also expect to see caution in TV channels' and news programs' approach to testing TikTok. We don't expect to find clear and universal strategy in their TikTok accounts, thus confirming previous studies. Finally, we assume there is interest and demand for news videos from younger audience, but TV news on TikTok has to be different and contain some 'fun' element to be directly consumed by the age group of 18-34.

\section{Methods}

This research was conducted in two stages. The first stage took place in the fall of 2020, when we analyzed the entire content of three news-related TikTok accounts: NBC News (one of the pioneers of professional TV news videos, registered back in 2019), Sky News and RT (Russian version). We also noted the existence of verified CNN account; however, it contained no videos and for this reason was not analyzed. Considering different span of their presence on TikTok 
we decided to analyze all the videos posted there through early September 2020. The number of videos in TV news channels' accounts ranged from 26 to 133.

The second stage was carried out from December 2020 through March of 2021. We revisited the accounts of news channels to check the dynamics of their posts and statistics and to analyze their activity over 2020. We found out that two of the accounts - Sky News and RT Russian - had significant changes. Sky News stopped posting new videos in August 2020, and RT's news account was no longer available (as of March 15th, 2021 TikTok offers only the RT documentaries channel, RTD).

This discovery made us modify our further focus and closely research two most active and so far, most successful (in terms of followers and likes) TV news accounts on TikTok - NBC News (@nbcnews, started in February 2019) and CBS News (@cbsnews, started in August 2020). Of course, both of them are not the traditional 24-hour news channels, but rather the news departments of the two oldest American TV networks, NBC and CBS.

To study their activity, we compiled a sample of news videos. We decided to pick four random weeks over the 5-months period of 2020 (since CBS News debuted only on August 1, 2020, we picked the same chronological period for NBC News): the week of August 31st - September 6th, the week of October 5 th - October 11th, the week of November 9th - November 15th, and the week of December 14th - December 20th, 2020. The total number of videos in this sample is 159 .

To analyze the audience preferences, we picked the top-10 most viewed, most liked, most commented on and most shared posts for each channel since the start of the account activity through December 31st, 2020, as it was crucial for us to understand the topical preferences of the audience and the potential life span of news videos on TikTok. Overall, there were 699 videos in this sample (544 CBS and 155 NBC posts in 2020), out of which we picked 80 most watched, most liked, most commented on and most shared.

Some of the main methods used in this research include quantitative and qualitative content analysis. We closely looked at the format, topics and popularity of posts. We paid special attention to finding non-traditional production techniques aimed at following TikTok standards and reaching its users (using hashtags, fonts, original sound versus TikTok soundtracks and overall presentation).

For RQ5 we also conducted a survey among 291 respondents in the age group of 18-34 from 18 different countries (Belgium, Brazil, Bulgaria, Canada, China, Denmark, France, Germany, Italy, Japan, Netherlands, Pakistan, Poland, 
Romania, Russia, Slovenia, Spain, UK). We asked them about their online news viewing habits and the potential demand for TV news on TikTok. This survey has some limitations: all of the respondents were undergraduate or graduate university students; most of them (85\%) were completing their studies in Lomonosov Moscow State University; most of them (98\%) were 20-24 years old, the other $2 \%$ were between the ages of 25 and 34 . This aspect definitely needs further research aiming to analyze audience demand and therefore surveying a larger and more representative group of respondents. Nevertheless, the represented diversity and the general unity in the answers we've got so far gives us an understanding of the question we are mostly interested in: is there a demand for short professional news videos on TikTok?

\section{Results}

Our research shows that there is definite interest - both on behalf of TV news channels and on behalf of the audience - towards using TikTok as one of the platforms for news video distribution. However, for different reasons the channels are showing caution in arriving onto TikTok. It is also clear that the selection and presentation of news here should be modified by creative young journalists who understand the algorithms of the platform and the demands of its audience.

RQ1: What are the main trends of the news channels' experience on TikTok so far and what kind of dynamics are they showing?

Back in the fall of 2020, during the first stage of our research, we found TikTok accounts of several large TV players from USA, Europe and Russia: CBS, NBC News, CNN, ESPN; BBC, Sky News, TF1 and RT (only its Russian version). There was no universal strategy, each channel was using this platform for different purposes: some posted news (NBC News, Sky News, RT), some used TikTok to promote their content and drive audience to the traditional TV screen (CBS, BBC).

We looked closely at the accounts of those channels which tried to present news content: NBC News (224 thousand subscribers, 4,3 mln likes); Sky News (18 thousand subscribers, 85,8 thousand likes); RT (nearly 5,5 thousand subscribers, 73,3 thousand likes) ${ }^{2}$. This difference we partially explained by the span of their presence on TikTok (NBC came there in February 2019, while Sky News and RT in March and July 2020).

We analyzed all the videos posted in these accounts to determine the most popular content in terms of views, likes and comments and realized that they differed for each channel:

${ }^{2}$ All the accounts' stats here are given as of September 2020. 
- The most popular videos on NBC News included social topics, showbiz, humor and politics;

- The most popular content on Sky News dealt with coronavirus news;

- The most popular videos on RT were about politics and different catastrophes.

We also wanted to analyze different tools the channels were using to enhance the visual and audial aspects of their product. The widest range was displayed in the account of NBC News (Table 1). NBC also stood out as the only account using TikTok anchor to present the majority of news videos.

Table 1

\section{Visual and audial content creation tools}

\begin{tabular}{|l|c|c|c|}
\hline \multicolumn{1}{|c|}{ Channel } & NBC News & Sky News & $\begin{array}{c}\text { RT (Russian } \\
\text { version) }\end{array}$ \\
\hline Visual content creation tools & \multicolumn{3}{c|}{} \\
\hline High quality video & + & + & + \\
\hline Mobile footage & + & + & + \\
\hline Security camera video & + & - & + \\
\hline Graphics & + & + & + \\
\hline Split screen anchor on camera & + & + & + \\
\hline Audial content creation tools & & + & + \\
\hline Original sound & + & + & - \\
\hline Music & + & - & \\
\hline Reporter's voice & + & & + \\
\hline
\end{tabular}

The average duration (total running time) of posted clips was the same for NBC News and Sky News (about 15-20 seconds) and longer for RT (20-45 seconds). The use of hashtags also differed for the three channels: Sky News posts contained 1-2 hashtags, RT used 2-5, while some NBC News posts had no hashtags at all (and some had up to five).

Overall, during the first stage of research we came to the following preliminary conclusions:

- there was no universal strategy for news channels on TikTok;

- Covid-19 did not seem to be the main content-maker;

- channels were still testing TikTok 'appliances' (hashtags, soundtracks etc.);

- TV channels were cautiously coming to the platform.

When we checked back in the first quarter of 2021 to measure the dynamics of news channels' activity on TikTok, we noted several significant changes: Sky News 
account was still on TikTok, but the activity there was halted (there had been no new video posts since August 2020); and the Russian version of RT's news account was no longer on TikTok (as of April 1, 2021 TikTok search for 'RT' returns only verified @russian_rtd account, which is RT's documentaries channel).

As we have learned, for Sky News this pause is temporary and is due to channel's 'finite resources'. They 'hope to be able to restart activity there as resources allow', as TikTok 'does have value for news'3.

Meanwhile, the accounts of NBC News and CBS News kept gaining new likes and subscribers. For example, the number of NBC News subscribers grew by $200 \%$ (from $224 \mathrm{~K}$ in the fall of 2020 to $678 \mathrm{~K}$ in early 2021), while the number of likes increased by $355 \%$ (from 4,3M to $19,6 \mathrm{M}$ ).

Thus, the answer to RQ 1 shows two distinct trends of news channels' activity on TikTok. On the one hand, we are witnessing obvious success for the TV news pioneers, which keep pushing their content on this platform. On the other hand, in case of relative newcomers, we are noting definite interest and desire to develop on TikTok, but finite human resources which limit the channels' options for active and aggressive growth there. Overall, as we are not fixing the surge in the number of news channels and TV news departments opening verified TikTok accounts, we can say that they are still using caution in conquering TikTok to attract the young audience.

RQ2: Which content and formats are the most successful news channels presenting on TikTok?

The second stage of our research focused on detailed analyses of the two most successful (as of early 2021) traditional news channel accounts on TikTok - NBC News (@nbcnews) and CBS News (@cbsnews). Both accounts represent American networks, which are part of the 'Big Three'. NBC was the first authorized TV channel in the U.S. (started broadcasting in 1941), followed shortly after by CBS. NBC also became the pioneer on TikTok, followed by CBS 17 months later. Table 2 gives a brief overview of some account statistics. Even though CBS News has a shorter TikTok experience, it has managed to gain more subscribers and likes and shows higher activity in terms of posts per day.

${ }^{3}$ From e-mail exchange with Nick Sutton, Head of Digital Output at Sky News.

The activity in the account resumed on July 28, 2021 
Table 2

Overview of news channels' TikTok activity

\begin{tabular}{|c|c|c|c|c|c|}
\hline Channel & $\begin{array}{c}\text { TikTok } \\
\text { debut }\end{array}$ & Subscribers* & Likes* & $\begin{array}{c}\text { Posts per day } \\
\text { (average) }\end{array}$ & $\begin{array}{c}\text { Average clip } \\
\text { duration }\end{array}$ \\
\hline NBC News & $\begin{array}{c}\text { February 22, } \\
2019\end{array}$ & $950,3 \mathrm{~K}$ & $29 \mathrm{M}$ & 1 & $23 \mathrm{sec}$ \\
\hline CBS News & $\begin{array}{c}\text { August 1, } \\
2020\end{array}$ & $1,6 \mathrm{M}$ & $106,3 \mathrm{M}$ & 5 & $30 \mathrm{sec}$ \\
\hline
\end{tabular}

"as of July 20, 2021

Our further analysis focused on the 4-week random sample of the two accounts. CBS News posted 131 videos over the chosen period, while NBC News had only 28 posts. We classified the formats used in the sample in order to understand what kind of content was offered as TikTok news. The results are shown in Table 3.

Table 3

TikTok formats, $\%$

\begin{tabular}{|c|c|c|}
\hline Format & NBC News & CBS News \\
\hline Soundbite & 29 & 59 \\
\hline Video + music & 14 & 15 \\
\hline Amateur video & 14 & - \\
\hline Anchor on camera tells & 43 & 1,5 \\
\hline Still pictures + music & - & 1,5 \\
\hline Highlights from TV interviews & - & 1,5 \\
\hline Video + soundbite & - & 4 \\
\hline Reporter standup & - & 3 \\
\hline Package highlights & - & \\
\hline
\end{tabular}

As we can see, there are only three formats, where the networks show some unity: regular soundbites (used on traditional TV as well), videos without voiceovers (but with background music) and amateur videos. Overall, the networks show a variety of other formats (wider on CBS News), most of which require special production and adaptation for TikTok.

One of the biggest differences between the two accounts is the presence of TikTok anchor in the NBC News videos. The female anchor is young, she is casually dressed, her hair and make-up styles are far from the traditional TV 
standards. Her 'down to Earth' approach can appeal to the young audience. When appropriate, she uses humor or sarcasm. Her high reading speed is fit for the TikTok format, as she manages to deliver more information in limited time. She usually appears on camera in front of the green screen chromakey or at home. Sometimes the news video or photo is taken fullscreen, with anchor on camera in the beginning and in the end of the clip.

RQ3: What kind of visuals, sound and fonts are they using? What kind of transformations are the texts in video description going through? What makes it different from traditional TV news?

First, let's look at the technical aspects of presenting information. We will go through visuals, sound tracks, fonts and texts NBC and CBS are using to create their TikTok product.

Video. As we found out, the channels are using both original and credited footage, but the ratio of their own and someone else's video is quite different: $39 \%$ of original footage for NBC versus $84 \%$ for CBS (Figure 1).

\section{Footage authorship}

Figure 1

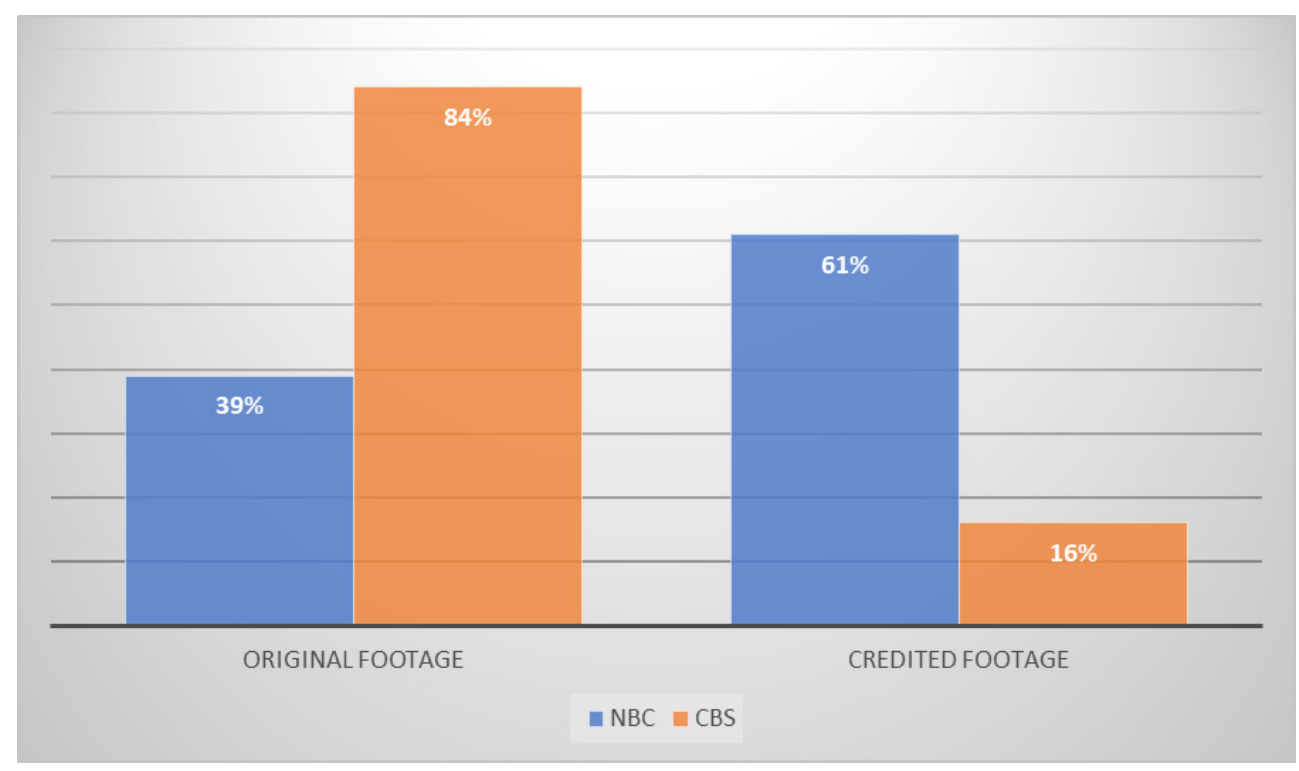

Also, $79 \%$ of CBS footage and only 32\% of NBC footage were shot professionally. The rest consisted of amateur video, security cameras footage and various soundbites from video conferences. 
Sound tracks. Here the picture for both accounts is very similar: $90 \%$ of news channels' content comes without any TikTok sounds (special sound tracks like songs or movie lines offered by the app). Only $10 \%$ of CBS and $11 \%$ of NBC clips use these options. Built-in background music is part of nearly one third of NBC clips, while CBS prefers to present most of its product without musical sound tracks of any kind (Figure 2).

Figure 2

\section{The use of music}

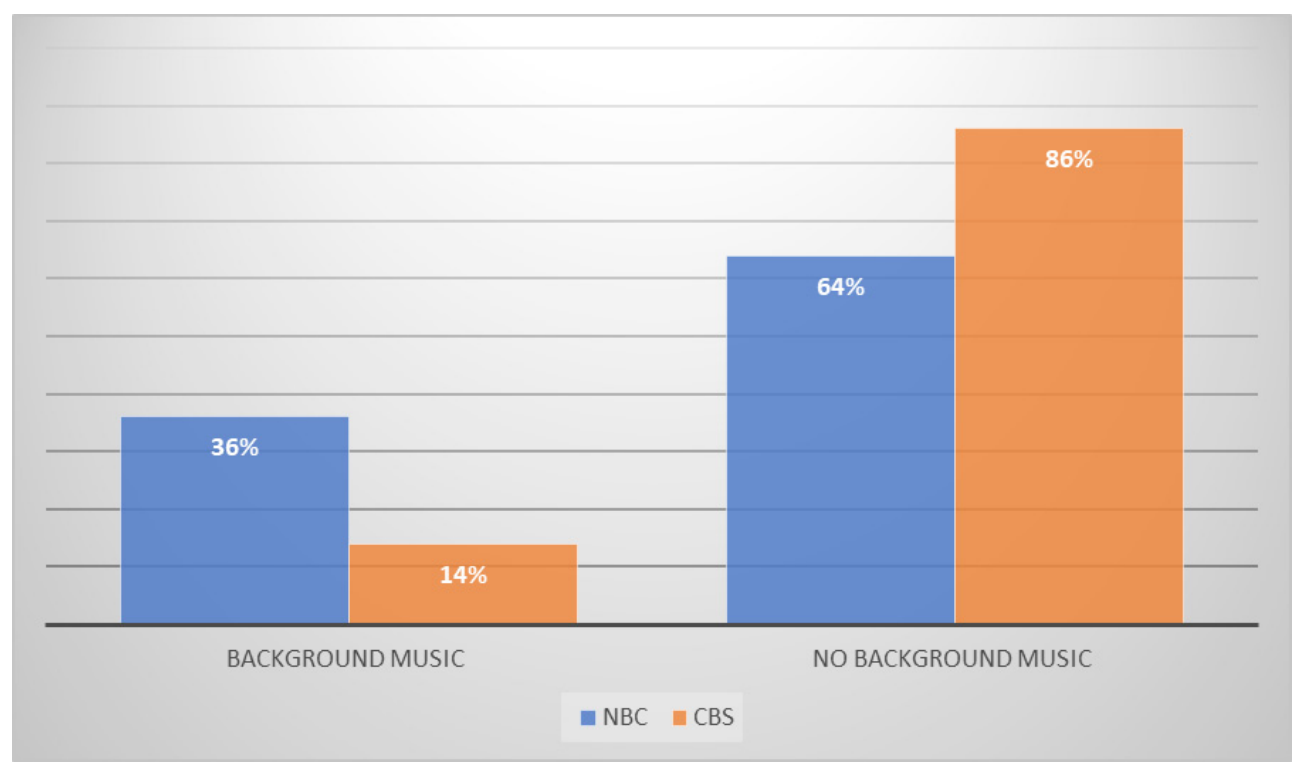

Fonts. We found three kinds of fonts in our sample:

- big headlines usually found at the account page without playing the clip; they function as titles overlaying the center of the clip;

- descriptive banners telling the gist of the story;

- technical fonts (locations, names, file footage etc.)

Big headlines are more popular with CBS (Figure 3). They let the users learn what the story is about just by looking at the timeline page. Since there is no need to play and watch the entire clip, these headlines are meant to serve as clickbait. For example: 'Snow covers woman clearing off roof' (CBS News, December 18, 2020), 'Sir Ian McKellen gets COVID-19 vaccine' (CBS News, December 17, 2020), 'Santa \& His Elf Bust Suspected Thieves' (NBC News, December 15, 2020), 'A Petition Against Boneless Wings' (NBC News, September 2, 2020). 


\section{The use of headline fonts}

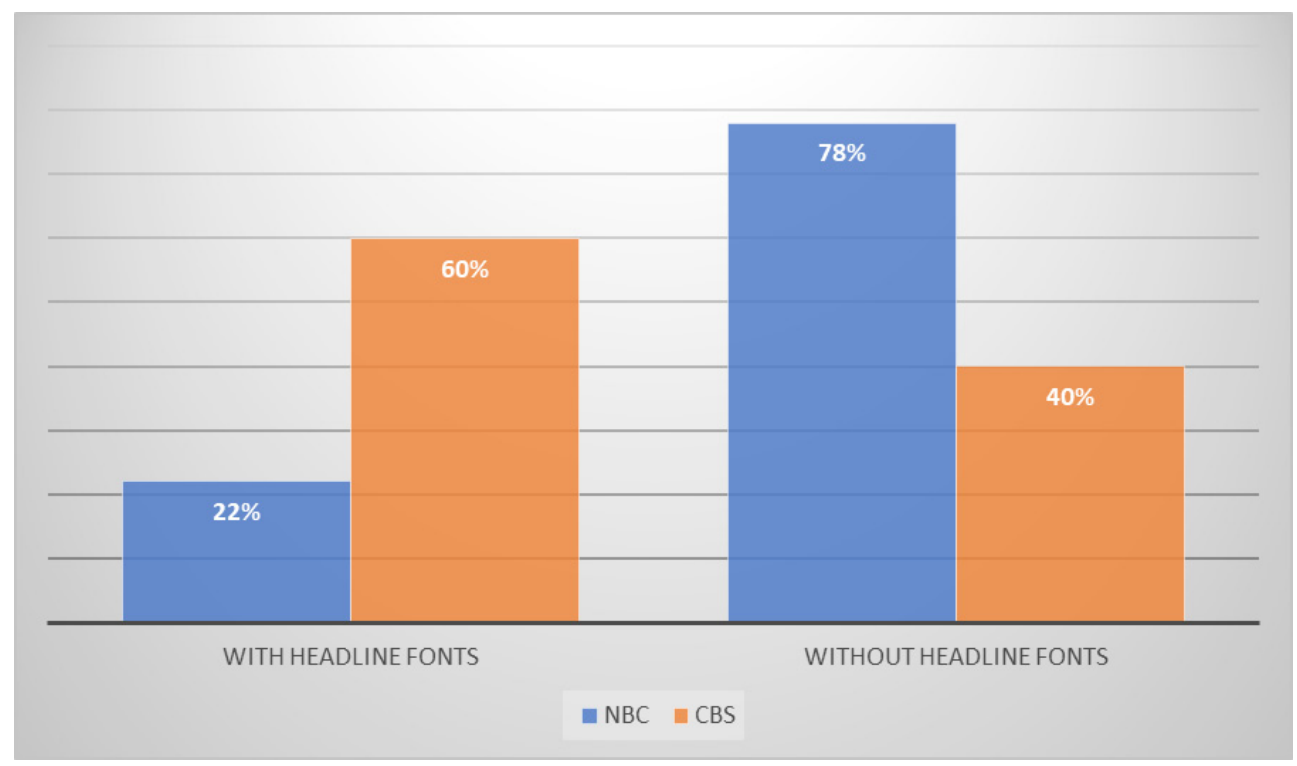

Descriptive fonts are found within the clip and tell the story to those who prefer to watch with sound off. Again, CBS tends to use them more often than NBC (Diagram 4). 99\% of CBS clips come with some kind of fonts, whether it is a combination of both headline fonts and descriptive fonts or headline fonts only. Only $1 \%$ of clips in the CBS sample was unfonted. NBC, on the other hand, posts $21 \%$ of clips fonts-free and uses descriptive fonts only in $68 \%$ of its product. 
Figure 4

The use of fonts

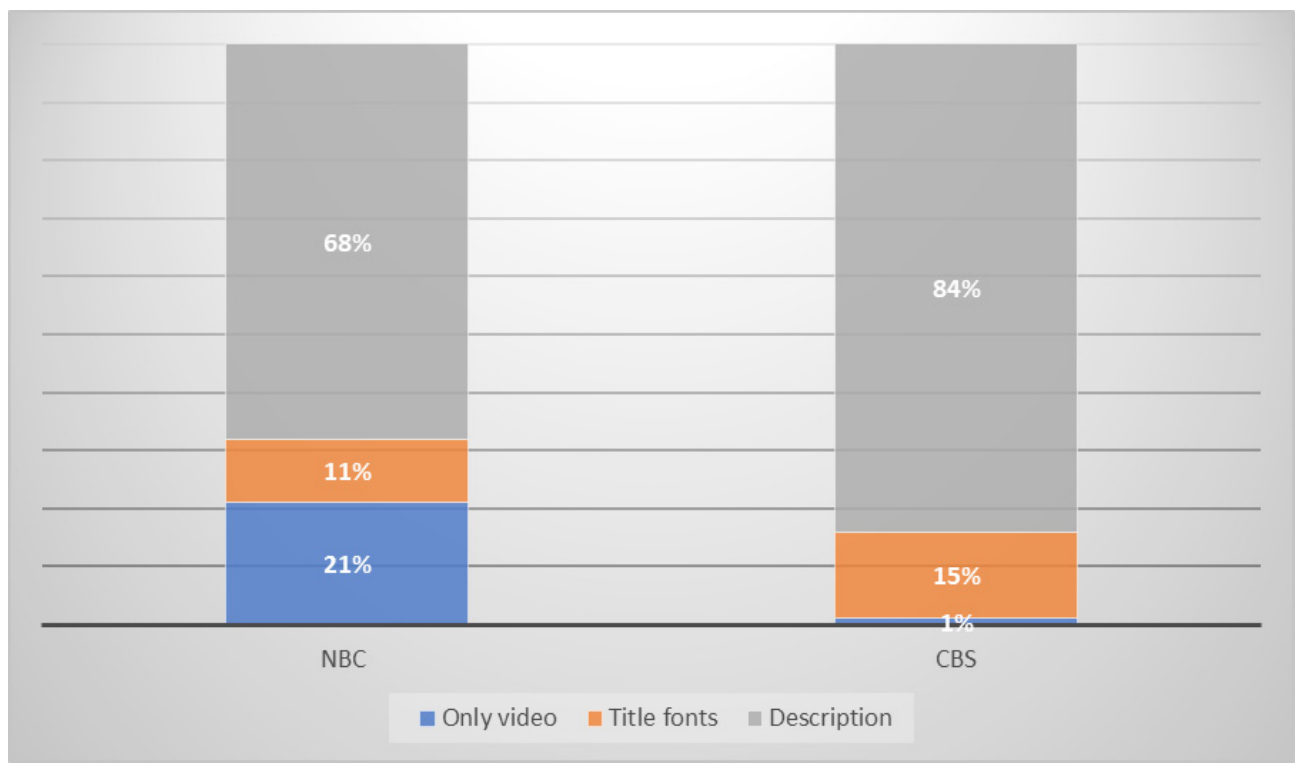

Technical fonts like speakers' and reporters' names, geographic locations and 'file' fonts are used only by CBS. NBC does not use this kind of fonts for TikTok, which is significantly different from standard television practices.

Finally, there is one more font-related observation concerning CBS practices. CBS consistently uses red to font Donald Trump and other members of Republican party, turquoise - to font Democrats, white - to font CBS reporters and other speakers besides politicians, and black is used for stories about natural disasters and various tragedies. For all the Covid-19 related news the company picked violet. NBC uses white to font all of its speakers within the big headlines.

Texts. We analyzed all the texts accompanying video posts in our sample. Our goal was to study the use of hashtags and emoji as popular tools of communication with the young audience on the one hand, and to look at the language used to deliver the news on the other hand. As it turned out, while two channels are similar in terms of emoji use, they differ considerably when it comes to hashtags and language.

Emoji. Emoji have become a part of social networks and messengers communication culture (Danesi, 2017; Sampietro, 2020), and they are believed to be especially popular with younger audience (Prada et al, 2018). We expected 
to find a wide use of emoji on TikTok platform by the news channels as well. However, only $3 \%$ of CBS posts and $11 \%$ of NBC posts contain these images of modern communication. Another $71 \%$ of NBC posts use the image of photo camera to credit the sources of video (this practice is widely used in social networks). Here are some examples of the posts containing emoji:

Would this 'monster wolf' scare you off?! (0) OHT: OHT SEIK (NBC News, December 11, 2020)

This \#Amazon driver took a moment to \#pray after delivering supplies to an infant with medical needs $\bigcirc \quad$ \#uplift (CBS News, September 5, 2020)

As we can see, there are definite emotions indicated by the emoji, but they are not overused (in fact, they are barely used at all).

Hashtags. TikTok hashtags strategy turned out to be significantly different for the two accounts we studied. While NBC rarely uses any hashtags in its posts (we found just two hashtags (7\%) in the 28 posts in our sample), for CBS they are a must. On average, there are three hashtags per post, and 98\% of CBS videos contain them in their description.

Language. Language is the area where we found significant differences in the style of presenting information. The posts in the CBS TikTok account were far from the language of broadcast news and close to print. The posts in the NBC account are written in the style of broadcast journalism: they are conversational, and they use short simple sentences (Hall, 1971; Montgomery, 2007). However, both accounts use past tenses in about $15 \%$ of their posts.

One area where the two networks showed some unity is the number of sentences used in the post description. Nearly all of them conveyed the key information in one sentence. And while CBS uses only straightforward declarative sentences (California ICU nurse breaks down while explaining the challenges of working through the pandemic. \#news \#coronavirus), NBC offers more natural to spoken speech and broadcast language variety of interrogative and exclamatory phrases (Table 4), for example: How much is too much snow? Watch these 8-inch figures get completely buried by the snow in Apalachin, NY. 우: Ron Murphy.

Table 4

\section{Post descriptions: Sentences}

\begin{tabular}{|l|c|c|c|c|c|c|}
\hline \multirow{2}{*}{ Channel } & \multicolumn{3}{|c|}{ Number of sentences, \% } & \multicolumn{3}{c|}{ Types of sentences, \% } \\
\cline { 2 - 7 } & $\mathbf{1}$ & $\mathbf{2}$ & $\mathbf{3}$ & declarative & interrogative & exclamatory \\
\hline NBC & 97 & 3 & - & 82 & 11 & 7 \\
\hline CBS & 98 & 1 & 1 & 100 & - & - \\
\hline
\end{tabular}


Another area where the networks demonstrate similar approach is the use of direct and indirect quotes as video description (usually these descriptions accompany soundbite posts). This group accounts for 35\% of CBS News posts and $21 \%$ of NBC News posts.

Biden on COVID-19: 'Let's end the politics and follow the science'. \#news \#biden \#coronavirus \#covid (CBS, October 7, 2020)

'Mr. Vice President, I'm speaking. I'm speaking'. (NBC, October 8, 2020).

We identified several verbal means of attracting users' attention and provoking the users to watch the video:

- imperative mood of the main verb in the sentence,

- the pronoun you addressing the user directly,

- and demonstrative pronouns this/these applying to the content in the video.

Here are some examples:

Take a moment to enjoy these undulating clouds in \#China \#relax\#nature (CBS, August 31, 2020)

Australia's Gold Coast had a foam party, but it's NOT what you think! Kellie Wilson \& Seven Network (NBC, December 16, 2020)

Kayakers were almost swallowed alive by this humpback whale. Kellie Balentine via TMX.news (NBC, November 10, 2020)

This is the area of the most significant differences in the two approaches. NBC News shows more variety and higher ratio of attraction means (Table 5).

Table 5

Post descriptions: Attraction means, \%

\begin{tabular}{|c|c|c|c|}
\hline Channel & Imperative mood & You & This/these \\
\hline NBC & 11 & 11 & 18 \\
\hline CBS & 5 & - & 4 \\
\hline
\end{tabular}

At the same time, the use of past tenses, not recommended for conversational style of broadcast news, is slightly more typical for NBC News (18\%) rather than CBS News (14\%).

Overall though, the language used in post descriptions is simple and mostly conversational. The use of different attraction means and emoji makes it more engaging for younger audience. However, both channels demonstrate different extent of entertainment and serious approach to match the news content of posted videos. 
RQ4: Which news topics does the audience prefer?

The answer to this question is not very surprising. The top category in all aspects (most watched, liked, commented on and shared) is politics. But first, to get the sense of audience interest, let's look at the highest numbers in each category (Table 6).

Table 6

The most popular videos statistics (2020)

\begin{tabular}{|c|c|c|c|c|}
\hline & Views & Likes & Comments & Shares \\
\hline CBS News & $15,6 \mathrm{M}$ & $2,6 \mathrm{M}$ & $61,5 \mathrm{~K}$ & $263,2 \mathrm{~K}$ \\
\hline NBC News & $6,8 \mathrm{M}$ & $1,4 \mathrm{M}$ & $24,3 \mathrm{~K}$ & $30,5 \mathrm{~K}$ \\
\hline
\end{tabular}

These numbers can compare with views, likes and shares some of the top TikTokers get on their videos ${ }^{4}$, but of course they are far from any top records.

As for the topical preferences, in the 80 analyzed videos we singled out the following categories:

Politics - mostly public figures' statements on America's internal and external affairs

Covid-19 - various pandemic news and events

Politics + Covid-19- hybrid category combining politicians' statements and actions on Covid-19

Human interest - news and events on various topics concerning 'people stories'

Politics + human interest - another hybrid category combining human interest stories with politicians as main newsmakers

Catastrophes - tragic events, in our sample mostly caused by natural disasters.

Now let's look at the ratio of each category in the top-10 most popular videos for CBS News and NBC News (Figures 5-8).

${ }^{4}$ For example, Loren Gray's (@lorengray), one of the top TikTokers', video from December 5, 2020 got 5,6 million likes and 38,5 million views. 
Figure 5

Topical categories ratio for the top-10 most watched videos

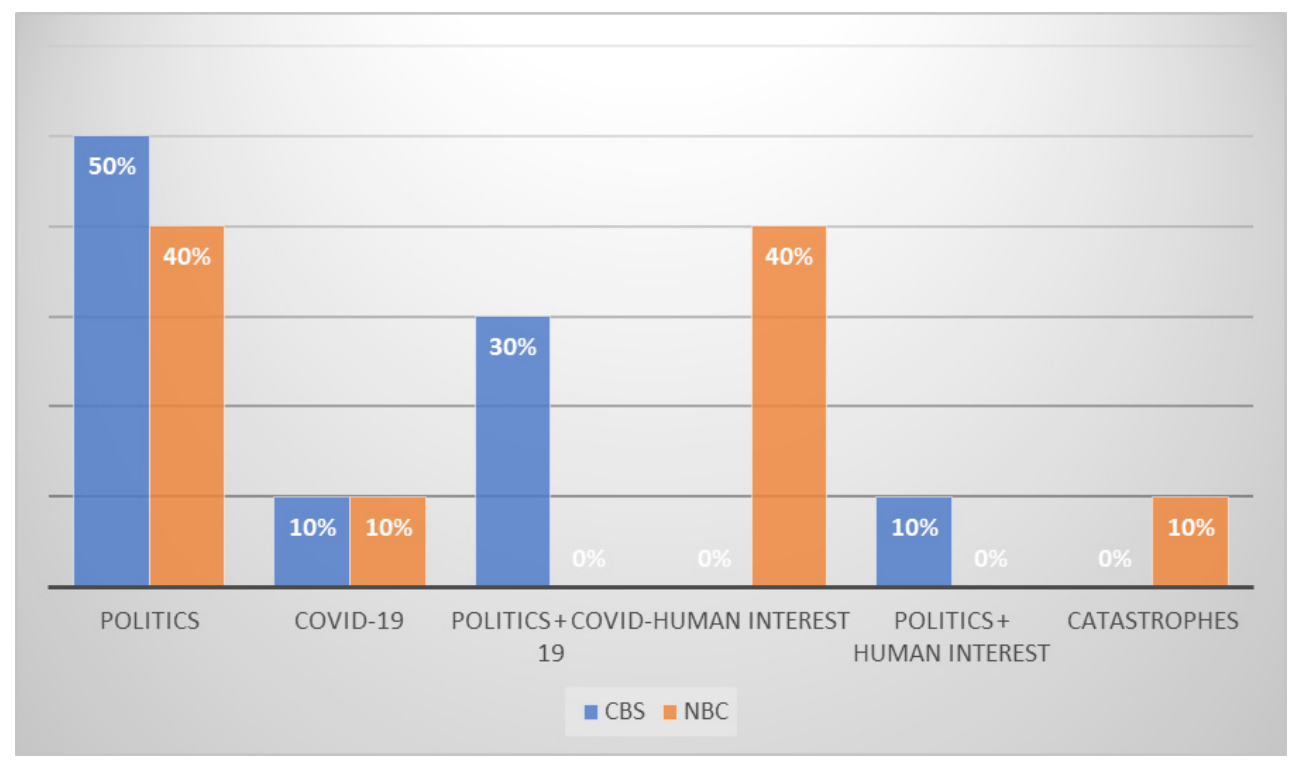

Figure 6

Topical categories ratio for the top-10 most liked videos

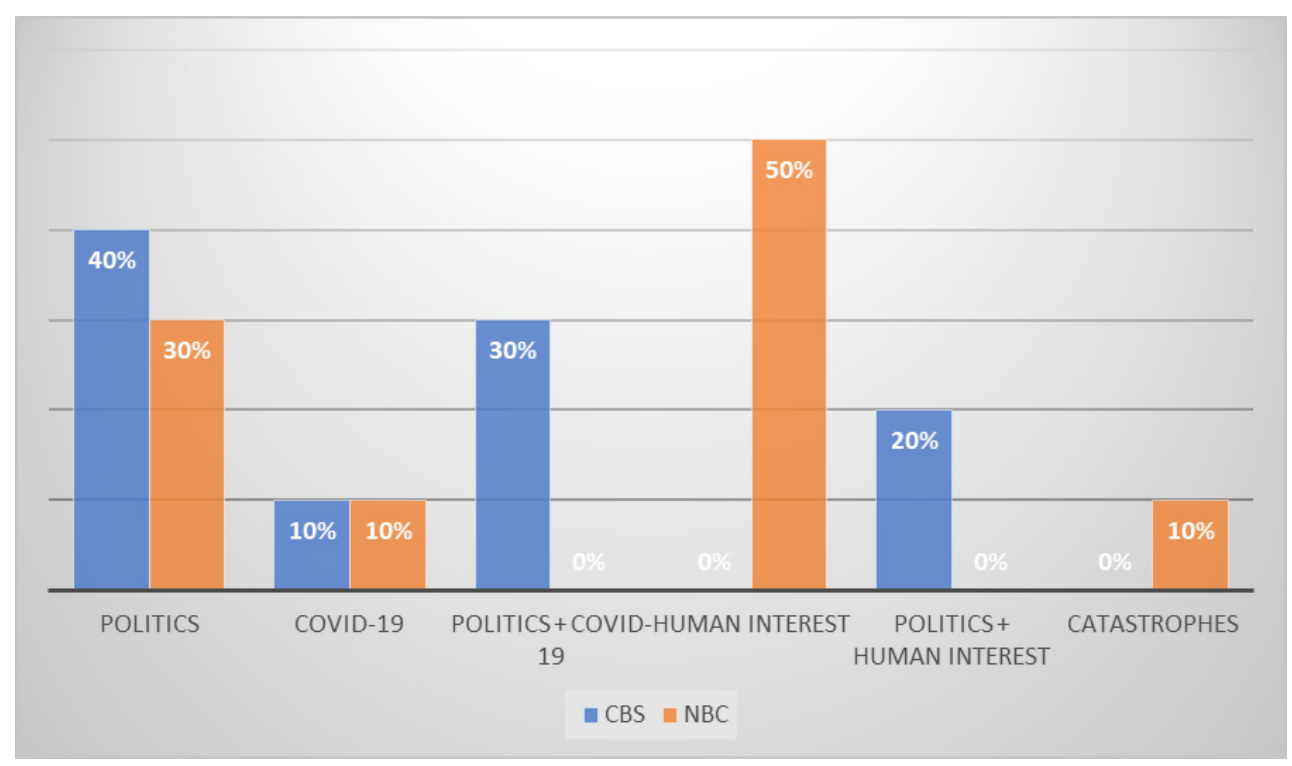


Figure 7

Topical categories ratio for the top-10 most commented on videos

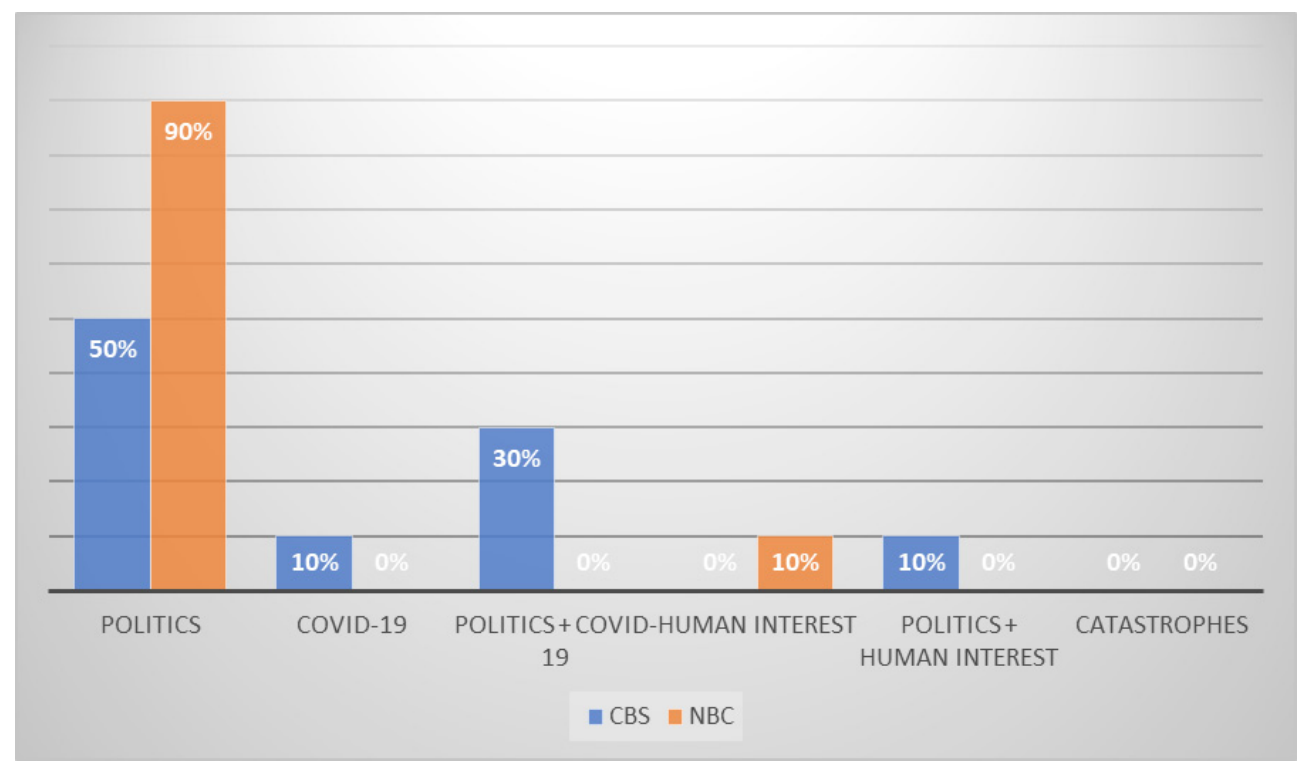

Figure 8

Topical categories ratio for the top-10 most shared videos

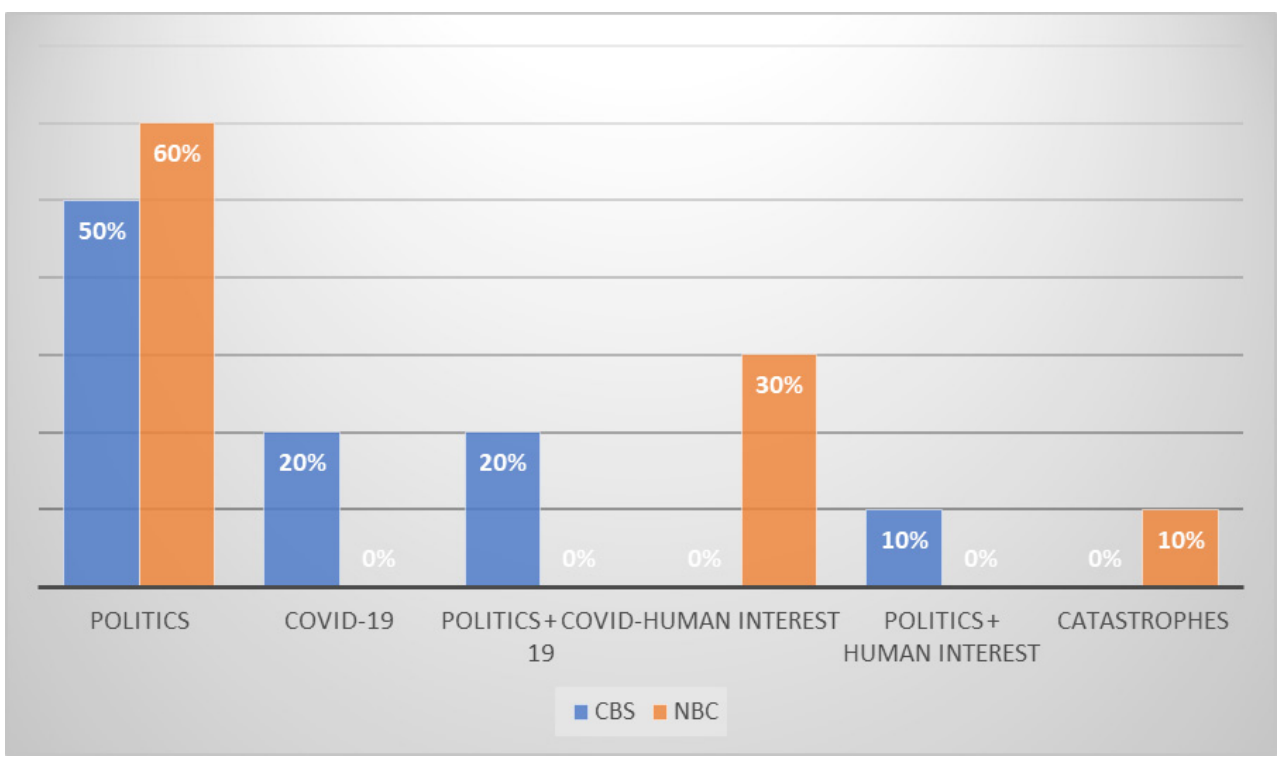


As we can see, for CBS audience reaction is more or less the same: Politics, Covid-19, Politics +Covid-19 and Politics + Human interest remain the top categories for all kinds of audience response (views, likes, comments and shares). It is a different story for the NBC account: different topical categories get different audience responses (Politics leads in comments and shares, while Human interest stories get more views and likes).

This is further broken down in Tables 7-8, which compare top videos in all types of audience reactions. As we can see, the popularity of the top six videos for CBS is identical in terms of views, likes, comments and shares. People watch, like, comment and share the same type of content. Only four videos (\#\#7-10) get somewhat different audience response. With NBC there is far more diversity (\#\#4-10), and different types of content get different audience response. This can also be explained by the fact that CBS content is mostly political and less diverse to begin with.

Table 7

The most popular videos diversity (CBS)

\begin{tabular}{|c|l|l|l|l|}
\hline Video rating & Views & Likes & Comments & Shares \\
\hline $\mathbf{1}^{\text {st }}$ & & & & \\
\hline $2^{\text {nd }}$ & & & & \\
\hline $3^{\text {rd }}$ & & & & \\
\hline $4^{\text {th }}$ & & & & \\
\hline $5^{\text {th }}$ & & & & \\
\hline $6^{\text {th }}$ & & & & \\
\hline $7^{\text {th }}$ & & & & \\
\hline $8^{\text {th }}$ & & & & \\
\hline $9^{\text {th }}$ & & & & \\
\hline $\mathbf{1 0}^{\text {th }}$ & & & & \\
\hline
\end{tabular}

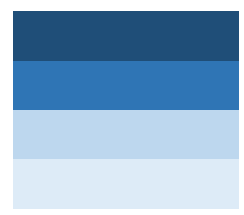

Sustained in 4 categories

Sustained in 3 categories

Sustained in 2 categories

1 category only 


\section{The most popular videos diversity (NBC)}

\begin{tabular}{|c|l|l|l|l|}
\hline Video rating & Views & Likes & Comments & Shares \\
\hline $\mathbf{1}^{\text {st }}$ & & & & \\
\hline $2^{\text {nd }}$ & & & & \\
\hline $3^{\text {rd }}$ & & & & \\
\hline $4^{\text {th }}$ & & & & \\
\hline $5^{\text {th }}$ & & & & \\
\hline $6^{\text {th }}$ & & & & \\
\hline $7^{\text {th }}$ & & & & \\
\hline $8^{\text {th }}$ & & & & \\
\hline $9^{\text {th }}$ & & & & \\
\hline $\mathbf{1 0}^{\text {th }}$ & & & & \\
\hline
\end{tabular}

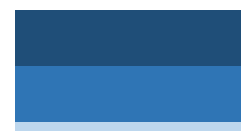

Sustained in 4 categories

Sustained in 3 categories

Sustained in 2 categories

1 category only

RQ5: Can TV news exist on TikTok from younger audience's perspective?

Finally, we decided to survey the potential audience in the targeted age groups of 18-14 and 25-34 and find out whether TV news is suitable for TikTok. We got 291 responses from 18 different countries (geographically we covered Europe, Russia, Asia, North and South America).

Overall, 74\% of respondents watch news videos online, 14\% prefer to read the news, and the rest are not interested in online news consumption at all. Those who do watch news videos prefer to do so on YouTube (43\%) or Instagram (19\%). Less popular responses included Telegram and Facebook. Only 1,5\% of respondents named TikTok as the platform of choice for news consumption.

One of the key questions in the survey was: 'Can TV news exist on TikTok?' As we found out, almost $75 \%$ of key demo agreed that in some form there is future for TV news on TikTok (Figure 9). 


\section{Can TV news exist on TikTok?}

Figure 9

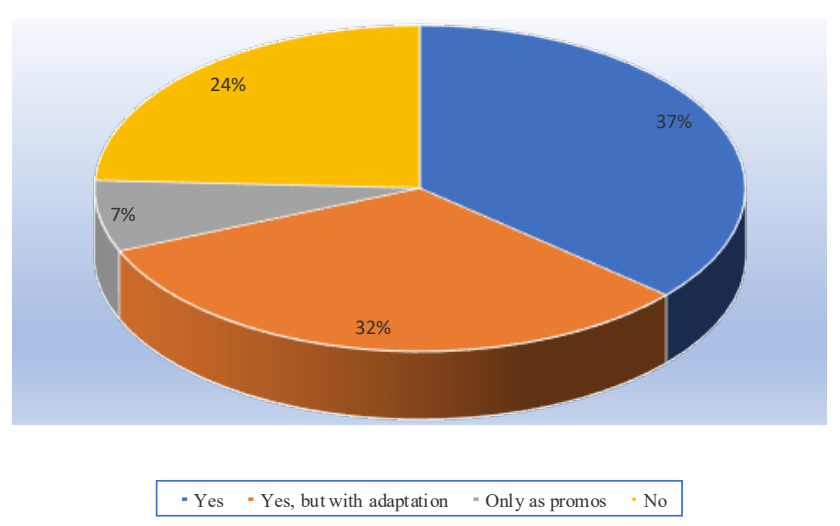

Here are some of the arguments we have received supporting the distribution of television news on TikTok:

- 'It's important for Generation Z. We can no longer consume 10-15-minute news. News has to be short, with pictures and interesting sound track';

- 'If people are ok with one-line news from online aggregators, why won't 15 seconds on TikTok be enough?';

- 'Not only news - talk shows and entertainment programs can exist on TikTok. The more information you pack into short amount of time, the better';

- 'Short news about sports, culture and lifestyle would be quite good on TikTok';

The ways to adapt the traditional news to TikTok, as seen by younger audience, are:

- 'Show news as super-fast changing pictures with clickbait headlines';

- 'In 30 seconds give the gist of the most important and most sensational stuff';

- 'Use more memes and jokes. Use only vertical videos';

- 'Traditional TV-reports won't work, but pictures with fonts will';

- 'A news piece can be presented as text with visual footage and music';

- 'No anchors, present news with text (both voiceover and fonts)';

- News on TikTok will work 'only for quick updates and not a full story'.

Among the arguments we received against news videos on TikTok are:

- 'We've got too much news everywhere. At least one platform has to remain news-free'; 
- 'TikTok is for entertainment, it won't work for serious news';

- 'Neither TikTok nor news need this. It's a bad idea to force the union of two completely different formats';

- 'People come here to relax, not to watch the news';

- 'TikTok can't be a credible source for mainstream news, maybe for a selected crowd but personally I can't take it seriously';

- 'You need a team of creative and motivated young people to make this work. [Russian] federal channels prefer old-fashioned methods, they change absolutely nothing in their programming'.

As we can see, the bottom line of news videos on TikTok for the younger audience comes to sensation, shortness and fun. It is not about in-depth reports, traditional and serious news, it is not about professional voiceovers of trained reporters and anchors, and it is not about traditional video editing techniques, where the frames are held for at least 3-4 seconds. It is about dynamics and entertainment, which are still widely associated with this platform.

\section{Conclusions}

To sum up, we can state that our hypothesis was mostly verified. It is obvious that TV news channels so far are very cautious about coming to TikTok, although some are starting to recognize the potential and are willing to put resources into this early testing stage.

There is no universal strategy for TikTok news content production, however there are some common trends that we are seeing in the accounts we analyzed: putting the stakes into political content, which remains highly popular with the users; posting soundbites, amateur video and video without voiceovers as some of the formats. Overall, we are noting a mix of traditional TV (regular soundbites) and adapted formats (brief highlights cut from reporters' packages, new anchor presentation style, heavy fonting).

Another trend is the shift in storytelling instruments: it is moving from spoken word (voiceover) towards written word (font), thus limiting the audial aspect of television to background music and TikTok sounds. This accommodates users to watch news clips with sound off without missing important information (which is also the trend for most of social networks today). The anchor role is also undergoing some crucial changes: from complete removal to transformation into casual 'anchorblogger' type presenter, who is trying to inform and entertain at the same time.

Entertainment part is one of the must-have attributes the young audience wants to see in TikTok news formats. In fact, the ideal news video, in the eyes of young consumers, must be short but informative, with information presented textually in 
fonts over interesting pictures rather than voiced over by anchors. This is definitely a challenge for TV channels, especially when it comes to serious news stories.

In this respect news channels are trying to find the right note in post descriptions, where the scarce use of emoji reflects the dilemma between serious and entertaining presentation. The language in post descriptions so far is a blend of conversational (TV) and official (newspapers) style and remains one of the areas for development.

Finally, active use of hashtags shows more success in terms of likes and views (CBS News) as opposed to poor hashtags use (NBC News).

So, how do these TV news accounts fit in within the rest of the TikTok trends and news media experiences on this platform? On the one hand, with NBC News and CBS News there is definite attempt to communicate news-related information in the short form, which makes them stand out from, for example legacy newspapers like The Washington Post or New York Post. The latter are mostly exploring the entertainment aspect of TikTok and producing soft news content or viral videos loosely related to news (Klug, 2020). On the other hand, certain rules of TikTok behavior - short form of videos and their predominantly entertaining bias - set their limits for storytelling instruments and topical variety. Hence, the abandonment of voiceover narrative, the use of TikTok sounds, the new presenter techniques incorporating humor when possible and some sensational soft news content along with popular mostly political news agenda.

These early experiences combined with our survey results prove that TikTok can very well be a platform for quick and attractive ways to tell the news, but the traditional TV networks have to further explore the reinvention of television for social networks and find more ways to combine traditional content production with modern 'on the go' content consumption.

\section{Acknowledgements}

We would like to thank Faculty of Journalism, Lomonosov Moscow State University staff member Kseniya Martemyanova, as well as graduate students Alyona Tikhonova, Sophiya Guleishvili and Anastasiya Nazarenko for their help with query data collection for this article.

\section{References}

BASCH, C., HILLYER, G. C., \& JAIME, C. (2020). COVID-19 on TikTok: Harnessing an emerging social media platform to convey important public health messages. International Journal of Adolescent Medicine and Health. Available from: https://doi.org/10.1515/ijamh-2020-0111 
CHOBANYAN, K. (2020). Up for a challenge? Digital practices of 24-hour news channels. World of Media. Journal of Russian Media and Journalism Studies, 3. DOI: $10.30547 /$ worldofmedia.3.2020.2

DANESI, M. (2017). The semiotics of emoji: The rise of visual language in the hasage of the Internet. London, UK/New York, NY, Bloomsbury.

DOYLE, B. (2021). TikTok statistics. Available from: https://wallaroomedia. com/blog/social-media/tiktok-statistics / [Accessed 5th August 2021].

ESCAMILLA-FAJARDO, P., ALGUACIL, M., \& L PEZ-CARRIL, S. (2021). Incorporating TikTok in higher education: Pedagogical perspectives from a corporal expression sport science course. Journal of Hospitality, Leisure, Sport and Tourism Education. Available from: https://doi.org/10.1016/j.jhlste.2021.100302

GAVRA, D., \& BYKOVA, E. (2021). Mediatized protest mobilization on social networks: Algorithms for building speech strategies. Vestnik Moskovskogo Universiteta. Seriya 10. Zhurnalistika, 2, p. 3-24.

GEYSER, W. (2021). TikTok statistics: Revenue, users and engagement stats. Available from: https://influencermarketinghub.com/tiktok-stats/ [Accessed 1st March 2021].

HALL, M. (1971). Broadcast journalism: An introduction to news writing. New York.

KLUG, D. (2020). 'Jump in and be the part of the fun'. How U.S. news providers use and adapt to TikTok. Midwest Popular Culture Association/Midwest American Culture Association Annual Conference (MPCA/ACA), October 0105, 2020, Minneapolis (virtual), USA. Available from: https://www.academia. edu/45470508/_Jump_in_and_be_Part_of_the_Fun_How_U_S_News_Providers_ Use_and_Adapt_to_TikTok [Accessed 15th September 2021].

LOVETT, J. T., MUNAWAR, K., MOHAMMED, SH., \& PRABHU, V. (2021). Radiology content on TikTok: Current use of a novel video-based social media platform and opportunities for radiology. Current Problems in Diagnostic Radiology. Available from: https://doi.org/10.1067/j.cpradiol.2020.10.004

MANDER, J., BUCKLE, CH., \& MORAN, SH. (2020). Global WebIndex's flagship report on the latest trends in social media. Available from: https:// www.globalwebindex.com/hubfs/Downloads/Social\%20flagship\%20report\%20 Q3\%202020\%20-\%20GlobalWebIndex.pdf?utm_campaign=Generic $\% 20$ nurture\%202019\&utm_medium =email\&_hsmi=92167087\&_hsenc=p2ANqtz-cUiGbKdealo-T8DeH3UV8-iFnGDtwb5DxzoDGMWOpeXZv9pniPC2gcEgq_fhwy i4BoshYKXTgIrrEoYe1vudRhikTwA\&utm_content =92167087\&utm_source $=$ hs_ automation [Accessed 10th March 2021].

MONTGOMERY, M. (2007). The discourse of the broadcast news: A linguistic approach. London. 
NEWMAN, N. (2020). Executive summary and key findings of the 2020 report. Reuters Institute for the study of journalism. Available from: https://www. digitalnewsreport.org/survey/2020/overview-key-findings-2020/ [Accessed 20th February 2021].

NEWMAN, N. (2021). Executive summary and key findings of the 2021 report. Reuters Institute for the study of journalism. Available from: https: / / reutersinstitute. politics.ox.ac.uk/digital-news-report/2021/dnr-executive-summary___Accessed 15th September 2021].

NIGMATULLINA, K. (2021). The role of social networks in the development of regional journalism in Russia. Vestnik Moskovskogo Universiteta. Seriya 10. Zhurnalistika, 1, p. 30-50.

NOVER, S. (2020). TikTok is growing up, and so are its users. Adweek. Available from: https://www.adweek.com/performance-marketing/tiktok-is-growing-upand-so-are-its-users / [Accessed 20th March 2021].

PRADA, M., RODRIGUES, D.L., GARRIDO, M.V., LOPES, D., CAVALHEIRO, B., \& GASPAR, R. (2018). Motives, frequency and attitudes toward emoji and emoticon use. Telematics and Informatics, 35(7), pp. 1925-1934. DOI: 0.1016/j.tele.2018.06.005

QIYANG, Z. \& JUNG, H. (2019). Learning and sharing creative skills with short videos: A case study of user behavior on TikTok and Bilibili. International Association of Societies of Design Research Conference, September 02-05, 2019, Manchester Metropolitan University, UK. Available from: https://iasdr2019.org/uploads/files/ Proceedings/le-f-1209-Zho-Q.pdf [Accessed 14th March 2021].

REMPEL, S. (2020). TikTok for news: Why there is a place for journalism on the app. The Canadian journalism project. Available from: https://j-source.ca/article/tiktok-fornews-why-theres-a-place-for-journalism-on-the-app/ [Accessed 10th February 2021].

SAMPIETRO, A. (2020). Use and interpretation of emoji in electronic-mediated communication: A survey. Visual Communication Quarterly, 27(1), pp. 27-39. Available from: https://doi.org/10.1080/15551393.2019.1707086

SERRANO, J., PAPAKYRIAKOPOULOS, O., \& HEGELICH, S. (2020). Dancing to the partisan beat: A first analysis of political communication on TikTok. Southampton '20: 12th ACM Conference on Web Science, July 7-10, 2020, Southampton, UK. ACM, New York, NY, USA. Available from: https://doi.org/10.1145/1122445.1122456

SHEARER, E. \& MITCHELL, A. (2021). News use across social media platforms in 2020.PewResearchCenter.Availablefrom:https://www.journalism.org/2021/01/12/ news-use-across-social-media-platforms-in-2020/ [Accessed 1st March 2021].

VARTANOVA, E., GLADKOVA, A., LAPIN, D., SAMORODOVA, E., \& VIKHROVA, O. (2021). Theorizing Russian model of the digital divide. World of Media. Journal of Russian Media and Journalism Studies, 1. DOI: 10.30547/worldofmedia.1.2021.1 
VARTANOVA, E. L., \& GLADKOVA, A. A. (2021). Digital Divide, Digital Capital, Digital Inclusion: Dynamics of Theoretical Approaches and Political Decisions. Vestnik Moskovskogo Universiteta. Seriya 10. Zhurnalistika, 1, p. 2-29.

VÁZQUEZ-HERRERO, J., NEGREIRA-REY, M.-C., \& LÓPEZ-GARCÍA, X. (2020). Let's dance the news! How the news media are adapting to the logic of TikTok. Journalism. Available from: https://doi.org/10.1177/1464884920969092

VÁZQUEZ-HERRERO, J., NEGREIRA-REY, M.-C., \& RODRÍGUEZ- VÁZQUEZ, A.-I. (2021). Intersections between TikTok and TV: Channels and programmes thinking outside the box. Journalism and Media, 2(1). Available from: https://doi. org/10.3390/journalmedia2010001

WANG, Y. (2020). Humor and camera view on mobile short-form video apps influence user experience and technology-adoption intent, an example of TikTok (DouYin). Computers in Human Behavior. Available from: https://doi. org/10.1016/j.chb.2020.106373

WANG, Y.-H., GU, T., \& WANG, S.-Y. (2019). Causes and characteristics of short video platform Internet community taking the TikTok short video application as an example. IEEE International Conference of Consumer Electronics - Taiwan (ICCE TW). DOI: 10.1109/ICCE-TW46550.2019.8992021

WILLIAMSON, D. A. (2020). TikTok users around the world 2020. eMarketer. Available from: https://www.emarketer.com/content/tiktok-users-aroundworld-2020 [Accessed 15th March 2021].

YU, J. X. (2019). Research of TikTok APP based on user-centric theory. Applied Science and Innovative Research, 3(1), pp. 28-36.

ZHANG, X., WU, Y., \& LIU, S. (2019). Exploring short-form video application addiction: Socio-technical and attachment perspectives. Telematics and Informatics. Available from: https://doi.org/10.1016/j.tele.2019.101243

ZHOU, Q. (2019). Understanding user behaviors of creative practice on short video sharing platforms - a case study of TikTok and Bilibili. (Electronic thesis or dissertation). Available from: https://etd.ohiolink.edu/ [Accessed 5th March 2021].

ZHU, C., XU, X., ZHANG, W., CHEN, J., \& EVANS, R. (2019). How health communication via TikTok makes a difference: A content analysis of TikTok accounts run by Chinese provincial health committees. International Journal of Environmental Research and Public Health. DOI:10.3390/ijerph17010192 